Revista Bioética

\title{
PESQUISA
}

\section{Quais são os valores morais essenciais para a formação médica?}

Lumaira Maria Nascimento Silva da Rocha Marques ${ }^{1}$, Sandra Costa Fonseca ${ }^{1}$, Vitor Corradini Milioni ${ }^{1}$, Weydler Campos Hottz Corbiceiro ${ }^{1}$

1. Universidade Federal Fluminense, Niterói/RJ, Brasil.

\section{Resumo}

Este estudo propõe identificar que valores morais os estudantes de medicina consideram importantes para sua formação e que valores a universidade tem promovido durante a graduação. Trata-se de estudo quantitativo, descritivo e transversal com 153 estudantes de universidade pública do estado do Rio de Janeiro. Os participantes consideraram respeito, responsabilidade, paciência e humildade como os valores morais mais importantes para a formação médica, e responsabilidade, respeito, paciência e prudência foram apontados como os mais estimulados durante a graduação. Os estudantes reconhecem a importância da educação moral para a formação profissional e se mostram sensíveis ao tema. Por conseguinte, é necessário capacitar docentes e instituir educação permanente para que a formação moral não seja produto da casualidade ou continue à margem dos currículos.

Palavras-chave: Educação médica. Ética. Princípios morais.

\section{Resumen}

\section{¿Cuáles son los valores esenciales para la formación médica?}

Este estudio tuvo como objetivo identificar los valores morales que los estudiantes de medicina consideran importantes para su educación y cuáles de estos valores la universidad ha promovido durante la graduación. Este es un estudio cuantitativo, descriptivo y transversal con 153 estudiantes de una universidad pública en el estado de Río de Janeiro, Brasil. Los estudiantes consideraron el respeto, la responsabilidad, la paciencia y la humildad como los valores morales más importantes para la educación médica. La responsabilidad, el respeto, la paciencia y la prudencia se señalaron como los valores más promovidos durante la graduación. Los estudiantes reconocen la importancia de la educación moral para la formación profesional y son sensibles al tema. Por lo tanto, es necesario planear capacitaciones e instituir una educación permanente para los docentes, para que la formación moral no sea producto de la casualidad ni continúe en la marginalidad de los planes de estudio.

Palabras clave: Educación médica. Ética. Principios morales.

\section{Abstract}

What are the moral values essential for medical training?

This study identifies which moral values medical students consider as important for their education and which ones university has promoted during the course. This is a descriptive cross-sectional study, with 153 students from a public university of Rio de Janeiro, Brazil. Students considered respect, responsibility, patience, and humility as the most important moral values for medical training, while responsibility, respect, patience, and prudence were pointed out as the most promoted values during their graduate course. They recognize the importance of moral education for professional training and are sensitive to the subject. Therefore, it is necessary to plan training and establish continuing education for professors so that moral formation does not become a product of chance neither continues in the curriculum background.

Keywords: Education, medical. Ethics. Morals. 
Que valores morais seriam essenciais para a boa formação médica? Essa pergunta permeia o imaginário de professores, alunos, pesquisadores e profissionais da saúde. Quando se imagina um bom médico, empatia, respeito, responsabilidade, humildade, bom raciocínio clínico, saber atender às necessidades do indivíduo e da comunidade e comportamento ético vêm à mente ${ }^{1}$. Nota-se que a lista enumera atributos relacionados a atitudes, caráter e expertise.

A herança positivista vem perdendo forças, e atualmente considera-se que valores morais têm grande importância na medicina, pois a técnica bem executada não garante sozinha a qualidade do atendimento ${ }^{1,2}$. Logo, a educação médica deve abarcar tanto formação técnica quanto moral, verdadeiramente indissociáveis, mesmo que sejam frequentemente apresentadas como incompatíveis ${ }^{3,4}$.

As Diretrizes Curriculares Nacionais de $2001^{5}$ e $2014{ }^{6}$ destacam a importância da formação concomitantemente generalista, humanizada, crítica, reflexiva e ética, para além do enfoque técnico. É necessário, portanto, transpor o paradigma biomédico e propor matriz curricular que fomente a responsabilidade social por meio da participação ativa do estudante na construção do conhecimento. Deve-se igualmente estimular a atuação em equipes multiprofissionais que priorizem o cenário da atenção primária para o cuidado em saúde com base nas ciências sociais, que abordam temas essenciais para a formação ética do estudante ${ }^{7}$.

Os valores morais são incorporados, por exemplo, mediante relações interpessoais de qualidade, reflexão e vivência de situações controvertidas, e a educação ajuda a promover princípios desejáveis para a sociedade ${ }^{8}$. Entende-se que é missão da universidade viabilizar a formação moral dos estudantes, ensinando-os, além dos aspectos técnicos do ofício, a ser, conviver, participar e habitar o mundo ${ }^{9,10}$. Dessa maneira, o ensino superior compromete-se com a educação moral dos indivíduos, dando sequência aos estímulos iniciados pela família e escola, compreendendo que esse processo é contínuo.

No entanto, quais valores morais devem ser ensinados na faculdade de medicina? Quais têm sido estimulados? Esses foram os questionamentos que impulsionaram esta pesquisa, cujo objetivo foi identificar que valores morais os estudantes consideram importantes para a formação médica e quais a universidade tem promovido durante a graduação. Vale ressaltar que serão enfatizados os valores do campo da moral e, portanto, não serão abordadas outras características do que se considera um "bom médico".
Neste artigo serão usadas as expressões "educação em valores", "educação moral" e "formação moral" como sinônimos, compreendendo que elas têm referenciais teóricos distintos, porém apresentam núcleo comum de discussão: o ensino das questões morais ${ }^{10}$.

\section{Método}

Realizou-se estudo quantitativo, descritivo e transversal com estudantes de faculdade pública de medicina do estado do Rio de Janeiro. Foram considerados elegíveis os discentes regularmente matriculados no oitavo período do curso no primeiro semestre de 2017 e 2018 ( $n=180)$. Excluíram-se os alunos envolvidos neste projeto de pesquisa $(n=2)$ e os que estiveram ausentes nos dias em que os dados foram coletados $(n=25)$, totalizando 153 participantes.

Os estudantes foram abordados em sala de aula, com permissão prévia do coordenador e do professor da disciplina. Os dados foram coletados por meio de questionário autoaplicado com 13 perguntas fechadas (Anexo). É importante ressaltar que isso ocorreu no último dia de aula do oitavo período, ou seja, quando os participantes já haviam cursado todas as disciplinas do currículo e passariam ao internato.

A primeira parte do questionário abrangia a identificação sociodemográfica dos participantes (idade, sexo, cor da pele, renda familiar, religião e estado civil), e a segunda parte abordava valores morais e a maneira como os estudantes percebiam sua intersecção com o curso. Os alunos assinalavam itens de múltipla escolha em resposta a questões que visavam identificar, entre outros dados, que valores morais os participantes consideram importantes para a formação, quais consideram que são estimulados ao longo do curso, quais disciplinas/atividades discutiram o tema e o quanto essa discussão contribui para a prática profissional.

Os valores morais indicados nessa parte do instrumento foram escolhidos com base nas virtudes aristotélicas e tomistas apresentadas por Maclntyre ${ }^{11}$. Este autor acredita que justiça, coragem, prudência, verdade, confiança, concórdia, humildade, generosidade, caridade, misericórdia, esperança, benevolência, gratidão e paciência são essenciais para que os indivíduos convivam harmoniosamente em sociedade. Acrescentaram-se "respeito" e "responsabilidade" a esta pesquisa por serem igualmente entendidos como valores morais importantes para a formação médica ${ }^{12}$. 
Os dados coletados foram processados e analisados com o pacote estatístico SPSS versão 17.0. Foram descritas frequências absolutas e relativas das variáveis referentes aos discentes e aos valores estudados. Todas as variáveis foram trabalhadas como categóricas, e suas proporções foram descritas. Posteriormente foram testadas associações entre características dos alunos e os valores mais prevalentes. Usou-se o teste qui-quadrado, e a significância foi estabelecida em $5 \%$.

Este estudo foi aprovado por Comitê de Ética em Pesquisa, e todos os participantes convidados foram devidamente informados e incluídos no estudo somente após assinarem o termo de consentimento livre e esclarecido.

\section{Resultados}

Dos 180 alunos elegíveis para o estudo, 153 (85\%) estavam presentes quando o questionário foi aplicado e todos se propuseram a responder às perguntas. A Tabela 1 descreve as características da amostra, predominantemente composta por mulheres $(57,5 \%)$, pessoas de 23 a 27 anos $(66,7 \%)$, de cor branca $(81,6 \%)$ e solteiras $(96,7 \%)$. Praticamente um quarto dos alunos afirmou não ter religião; entre os religiosos, predominaram católicos $(37,2 \%)$ e espíritas $(15,7 \%)$. Quanto à renda familiar, $53,6 \%$ recebem até 11 salários mínimos e aproximadamente um quarto recebe entre 17 e 22 salários mínimos.

Os valores morais assinalados como os mais importantes para a formação médica foram "respeito" $(93,5 \%)$, "responsabilidade" $(90,8 \%)$, "humildade" (83,7\%) e "paciência" (82,4\%). As mulheres assinalaram com mais frequência "responsabilidade" e "paciência", porém sem diferença estatística significante ( $p=0,06$ e $p=0,34$, respectivamente). Professar ou não alguma religião não levou os participantes a assinalar mais valores morais, e apenas $22(14,4 \%)$ estudantes, em sua maioria mulheres, assinalaram todas as opções. Os participantes consideraram que foram mais estimulados durante a graduação em medicina: "responsabilidade" (73,2\%), "respeito" (70,6\%), "paciência" (55,6\%) e "prudência" (45,1\%). Os demais valores apresentaram percentuais inferiores (Tabela 2 ).

Tabela 1. Dados sociodemográficos dos 153 estudantes de medicina participantes do estudo (Rio de Janeiro/RJ, 2017-2018)

\begin{tabular}{|c|c|c|}
\hline Variáveis & $\mathbf{n}$ & $\%$ \\
\hline \multicolumn{3}{|l|}{ Sexo } \\
\hline Feminino & 88 & 57,5 \\
\hline Masculino & 61 & 39,9 \\
\hline Não informado & 4 & 2,6 \\
\hline \multicolumn{3}{|l|}{ Faixa etária } \\
\hline 18-22 anos & 29 & 18,9 \\
\hline 23-27 anos & 102 & 66,7 \\
\hline 28-32 anos & 13 & 8,5 \\
\hline 33-37 anos & 5 & 3,3 \\
\hline Não informado & 4 & 2,6 \\
\hline \multicolumn{3}{|l|}{ Cor da pele } \\
\hline Branca & 125 & 81,6 \\
\hline Preta & 1 & 0,7 \\
\hline Parda & 26 & 17,0 \\
\hline Amarela & 1 & 0,7 \\
\hline \multicolumn{3}{|l|}{ Estado civil } \\
\hline Solteiro & 148 & 96,7 \\
\hline Casado & 5 & 3,3 \\
\hline \multicolumn{3}{|l|}{ Religião } \\
\hline Católica & 57 & 37,2 \\
\hline Espírita & 24 & 15,7 \\
\hline Evangélica & 17 & 11,1 \\
\hline Outra & 18 & 11,8 \\
\hline Sem religião (ateu/agnóstico) & 37 & 24,2 \\
\hline \multicolumn{3}{|l|}{ Renda familiar } \\
\hline 1-5 salários mínimos & 31 & 20,3 \\
\hline 6-11 salários mínimos & 51 & 33,3 \\
\hline 12-16 salários mínimos & 30 & 19,6 \\
\hline 17-22 salários mínimos & 40 & 26,1 \\
\hline Não informado & 1 & 0,7 \\
\hline
\end{tabular}

Tabela 2. Valores morais considerados importantes e estimulados no curso de medicina, segundo sexo (Rio de Janeiro/RJ, 2017-2018)

\begin{tabular}{l|c|c|c|c|c|c}
\multirow{2}{*}{ Valores } & \multicolumn{3}{|c|}{ Importantes } & \multicolumn{3}{c}{ Estimulados } \\
\cline { 2 - 7 } & $\begin{array}{c}\text { Mulheres } \\
\mathbf{n}(\%)\end{array}$ & $\begin{array}{c}\text { Homens } \\
\mathbf{n}(\%)\end{array}$ & $\begin{array}{c}\text { Total } \\
\mathbf{n}(\%)\end{array}$ & $\begin{array}{c}\text { Mulheres } \\
\mathbf{n}(\%)\end{array}$ & $\begin{array}{c}\text { Homens } \\
\mathbf{n}(\%)\end{array}$ & $\begin{array}{c}\text { Total } \\
\mathbf{n}(\%)\end{array}$ \\
\hline Responsabilidade & $84(95,5)$ & $55(90,2)$ & $139(90,8)$ & $71(80,7)$ & $41(67,2)$ & $112(73,2)$ \\
\hline Respeito & $85(96,6)$ & $58(95,1)$ & $143(93,5)$ & $64(72,7)$ & $44(72,1)$ & $108(70,6)$ \\
\hline Paciência & $75(85,2)$ & $51(83,6)$ & $126(82,4)$ & $53(60,2)$ & $32(52,5)$ & $85(55,6)$ \\
\hline
\end{tabular}


Tabela 2. Continuação

\begin{tabular}{l|c|c|c|c|c|c}
\multirow{2}{*}{ Valores } & \multicolumn{3}{|c|}{ Importantes } & \multicolumn{3}{c}{ Estimulados } \\
\cline { 2 - 7 } & $\begin{array}{c}\text { Mulheres } \\
\mathbf{n}(\%)\end{array}$ & $\begin{array}{c}\text { Homens } \\
\mathbf{n}(\%)\end{array}$ & $\begin{array}{c}\text { Total } \\
\mathbf{n}(\%)\end{array}$ & $\begin{array}{c}\text { Mulheres } \\
\mathbf{n}(\%)\end{array}$ & $\begin{array}{c}\text { Homens } \\
\mathbf{n}(\%)\end{array}$ & $\begin{array}{c}\text { Total } \\
\mathbf{n}(\%)\end{array}$ \\
\hline Prudência & $66(75,0)$ & $51(83,6)$ & $117(76,5)$ & $39(44,3)$ & $30(49,2)$ & $69(45,1)$ \\
\hline Confiança & $63(71,6)$ & $44(72,1)$ & $107(69,9)$ & $15(17,0)$ & $10(16,4)$ & $25(16,3)$ \\
\hline Justiça & $50(56,8)$ & $35(57,4)$ & $87(56,9)$ & $13(14,8)$ & $10(16,4)$ & $23(15,0)$ \\
\hline Misericórdia & $29(33,0)$ & $14(23,0)$ & $43(28,1)$ & $0(0,0)$ & $2(3,3)$ & $2(1,3)$ \\
\hline Esperança & $47(53,4)$ & $29(47,5)$ & $76(49,7)$ & $12(13,6)$ & $10(16,4)$ & $22(14,4)$ \\
\hline Verdade & $54(61,4)$ & $41(67,2)$ & $95(62,1)$ & $17(19,3)$ & $16(26,2)$ & $33(21,6)$ \\
\hline Generosidade & $62(70,5)$ & $33(54,1)$ & $95(62,1)$ & $26(29,5)$ & $13(21,3)$ & $39(25,5)$ \\
\hline Humildade & $77(87,5)$ & $51(83,6)$ & $128(83,7)$ & $39(44,3)$ & $18(29,5)$ & $57(37,3)$ \\
\hline Caridade & $40(45,5)$ & $22(36,1)$ & $62(40,5)$ & $11(12,5)$ & $7(11,5)$ & $18(11,8)$ \\
\hline Concórdia & $18(20,5)$ & $11(18,0)$ & $29(19,0)$ & $1(1,1)$ & $1(1,6)$ & $2(1,3)$ \\
\hline Benevolência & $36(40,9)$ & $18(29,5)$ & $54(35,3)$ & $7(8,0)$ & $8(13,1)$ & $15(9,8)$ \\
\hline Coragem & $56(63,6)$ & $32(52,5)$ & $88(57,5)$ & $22(25,0)$ & $12(19,7)$ & $35(22,9)$ \\
\hline Gratidão & $49(55,7)$ & $24(39,3)$ & $73(47,7)$ & $13(14,8)$ & $9(14,8)$ & $22(14,4)$ \\
\hline
\end{tabular}

As disciplinas mais assinaladas como tendo discutido ou proporcionado vivência sobre valores morais foram Semiologia (56,9\%), Trabalho de Campo I (49,7\%), Saúde e Sociedade I (45,8\%) e Ética (40\%). Outras, como Saúde e Sociedade II e Trabalho de Campo II, atingiram percentuais entre 20 e $39 \%$. As demais ficaram abaixo deste valor (Tabela 3).

Tabela 3. Relação do curso, professores e disciplinas com a formação moral e médica de estudantes de medicina (Rio de Janeiro/RJ, 2017-2018)

\begin{tabular}{|c|c|}
\hline Variáveis & $\begin{array}{l}\text { Respostas } \\
\text { n (\%) }\end{array}$ \\
\hline \multicolumn{2}{|l|}{ Disciplinas que discutiram valores morais* } \\
\hline Semiologia & $87(56,9)$ \\
\hline Trabalho de Campo I & $76(49,7)$ \\
\hline Saúde e Sociedade I & $70(45,8)$ \\
\hline Ética & $61(40,0)$ \\
\hline $\begin{array}{l}\text { Tutoria na Formação Médica; Psiquiatria } \\
\text { do Adulto; Psiquiatria Infantil; } \\
\text { Psicologia Médica; Trabalho de Campo } \\
\text { II e III; Saúde e Sociedade II, III e IV; } \\
\text { Doenças Infectoparasitárias; Vigilância } \\
\text { Epidemiológica; Dependência Química }\end{array}$ & $\begin{array}{l}31-60 \\
(20-39)\end{array}$ \\
\hline \multicolumn{2}{|l|}{$\begin{array}{l}\text { Tipo de atividade com maior influência na } \\
\text { formação moral* }\end{array}$} \\
\hline Vivência prática & $120(78,4)$ \\
\hline Atividade em pequenos grupos & $94(61,4)$ \\
\hline Discussão de casos & $63(41,2)$ \\
\hline Debates & $54(35,3)$ \\
\hline Aula expositiva & $23(15,0)$ \\
\hline \multicolumn{2}{|l|}{ Forma de influência das disciplinas } \\
\hline Implícita & $126(82,4)$ \\
\hline
\end{tabular}

continua...
Tabela 3. Continuação

\begin{tabular}{l|c} 
Variáveis & $\begin{array}{c}\text { Respostas } \\
\mathbf{n}(\%)\end{array}$ \\
\hline Explícita & $21(13,7)$ \\
\hline Não informado & $6(3,9)$ \\
\hline Relação docente-discente & $97(63,4)$ \\
\hline Vertical & $47(30,7)$ \\
\hline Horizontal & $9(5,9)$ \\
\hline Não informado & $121(79,1)$ \\
\hline Importância dos valores morais na prática médica \\
\hline Muita & $27(17,6)$ \\
\hline Pouca & $5(3,3)$ \\
\hline Nenhuma/não informado
\end{tabular}

*Mais de uma opção poderia ser marcada

A maioria dos estudantes $(78,4 \%)$ reconhece a vivência prática como melhor forma de estimular valores morais. Contudo, quase todos $(82,4 \%)$ apontaram que a temática se apresentou de maneira implícita nas disciplinas e atividades educativas, e $63,4 \%$ dos respondentes afirmaram que a relação entre professor e aluno é verticalizada. Por fim, $79,1 \%$ dos estudantes acreditam que a discussão sobre valores morais contribuirá significativamente para sua prática profissional (Tabela 3 ).

\section{Discussão}

A partir dos resultados apresentados, nota-se que os estudantes compreendem a importância dos valores morais na formação médica, mas identificam poucas situações de aprendizagem relacionadas a 
eles ao longo do curso. Estudos relatam que virtudes e valores morais se desgastam no decorrer da graduação ${ }^{13,14}$, mas nesta pesquisa, ainda que os participantes estivessem terminando o oitavo período e, portanto, já houvessem concluído todas as disciplinas e atividades que precedem o internato, se observou a manutenção dos valores, pelo menos de forma conceitual.

Os respondentes deste estudo valorizam principalmente respeito, responsabilidade, paciência, humildade, prudência e confiança como características mais importantes a serem trabalhadas na graduação. Em pesquisa com estudantes espanhóis da área da saúde os resultados foram semelhantes, sendo "responsabilidade" e "respeito" os princípios mais valorados ${ }^{12}$. Outro estudo similar concluiu que estudantes de enfermagem, medicina e odontologia também consideraram a formação moral essencial para a vida profissional, apontando "responsabilidade", "compromisso" e "ter valores éticos" como preceitos importantes a serem estimulados ${ }^{15}$.

Outros autores ${ }^{12,16}$ também não identificaram diferenças significativas entre os valores morais assinalados por homens e mulheres. Apesar disso, destaca-se que alguns valores, como "responsabilidade" e "paciência", foram mais assinalados por estudantes do sexo feminino, o que pode fomentar reflexões sobre gênero na formação moral e profissional ${ }^{17}$. Gilligan ${ }^{17}$ demonstrou que mulheres costumam interpretar dilemas morais como problemas de cuidado e, portanto, se apoiam em valores como responsabilidade, respeito, diálogo e paciência para tomar decisões.

A medicina, assim como outras profissões da área da saúde, trabalha com o cuidado, compreendido como o ato de ajudar o outro em sua necessidade. A ação de cuidar, inserida na esfera profissional, deve englobar tanto tarefas técnicas como atitudes, uma vez que empatia, compaixão, afeto e escuta também têm papel terapêutico ${ }^{9,18}$. Estes valores alinham-se à promoção de cuidado humanizado, tão preconizado na assistência à saúde ${ }^{9,14,19}$.

Valorar o cuidado humanizado é focar não apenas na doença, mas na vida humana. Trata-se de alterar paradigmas e formar profissionais com base nos princípios e diretrizes do Sistema Único de Saúde ${ }^{20}$. Essas transformações vão ao encontro das Diretrizes Curriculares Nacionais, que buscam fomentar mudanças que levem instituições de ensino superior a assumir compromisso ético-político com a formação em saúde ${ }^{21}$.

Os quatro valores mais escolhidos como estimulados ao longo da graduação de medicina foram "responsabilidade" $(73,2 \%)$, "respeito" (70,6\%), "paciência" (55,6\%) e "prudência" (45,1\%), constatando-se que a formação moral oferecida está aquém das expectativas dos alunos. Nota-se que o estímulo da responsabilidade e do respeito foi consideravelmente mais percebido que o dos demais valores. "Responsabilidade", entendida como a consciência sobre os próprios atos e a aceitação de suas consequências ${ }^{22}$, pode ter sido referida pelos estudantes em razão de vivências explícitas nas disciplinas de deontologia, que trabalham com o termo "responsabilidade profissional", previsto no Código de Ética Médica ${ }^{23}$ - ou implícitas - mediante o chamado "currículo oculto" 24.

Também é interessante abordar a noção de responsabilidade inserida no campo da moral, pois abarca a concepção de cuidado. A responsabilidade moral não é imposta por lei, mas resultado da consciência de pertencimento ao coletivo, o que gera sentimento de proteção, principalmente em relações assimétricas, como entre médico e paciente ${ }^{25}$. Os achados de Hernando e colaboradores ${ }^{12}$ também deram grande relevância à responsabilidade, sendo interpretados como resultado do amadurecimento dos estudantes e do desejo de aceitação social.

Por sua vez, "respeito" refere-se à forma como o indivíduo enxerga e se relaciona com o outro ${ }^{26}$. $O$ fato de os estudantes terem sido capazes de percebê-lo indica que este valor permeou as relações interpessoais ao longo da graduação, especialmente as profissionais. Ensinar moralmente inclui se relacionar de maneira respeitosa, responsável, humilde e paciente com discentes, pois é por meio dessa relação na qual se edificam os valores morais que o professor consegue estabelecer ambiente propício para o desenvolvimento cognitivo e moral do estudante ${ }^{27}$.

Apesar disso, ainda há contradição: a maioria dos estudantes reconhece o respeito como valor estimulado na graduação, mas ao mesmo tempo afirma que as relações interpessoais com seus professores são verticais e autoritárias. Se o docente valida formas abusivas de relacionamento, o estudante pode tomá-lo como modelo e reproduzir esse tipo de conduta na relação com outros indivíduos, inclusive na futura relação médico-paciente.

A presença de relações verticalizadas pode estar relacionada ao narcisismo existente nas universidades de maneira geral. Esse comportamento, adotado por alguns professores, pode ser explicado pela dificuldade de aceitar seu "não saber" 28. Assumir sua expertise como verdade absoluta prejudica a construção de novos saberes em conjunto 
com o outro e de momentos coletivos de reflexão e debate, como preconizado pelas novas metodologias de ensino-aprendizagem. Esse tipo de conduta pode explicar a intensa apreciação da humildade demonstrada pelos estudantes e a baixa percepção de situações envolvendo esse valor moral durante a graduação, indicando ainda que é possível aprender, com exemplos negativos, o que não se tornar.

Admitindo-se que a relação entre professor e estudante é relevante ferramenta para trabalhar a educação moral do aluno e considerando que as relações interpessoais influenciam a formação do indivíduo, essa temática não pode ser ignorada pelo planejamento docente. É preciso desconstruir o consenso de que o campo das relações interpessoais se refere somente à esfera individual, não sendo passível de intervenções e mudanças.

E como ensinar valores morais? A maioria dos estudantes desta investigação $(78,4 \%)$ reconhece que as vivências práticas são importantes para essa aprendizagem. Esse achado pode corroborar o estudo de Almeida e colaboradores ${ }^{29}$, que trouxe considerações relevantes sobre a inserção de estudantes de medicina na atenção primária à saúde desde o início do curso, auxiliando na formação de profissionais capazes de operar em outra lógica social.

As disciplinas que mais contribuíram para a discussão dos valores morais, segundo os respondentes deste estudo, foram Semiologia (56,9\%), Trabalho de Campo I (49,7\%), Saúde e Sociedade I $(45,8 \%)$ e Ética (40\%). Todas compartilham atividades como vivência prática e discussões em pequenos grupos, e a maioria delas tem em sua ementa conteúdos explícitos de formação humanística. Esperava-se percentual mais elevado, mas o fato de duas delas serem oferecidas no primeiro período do curso - estando, portanto, sujeitas a viés de memória - pode ter contribuído para o baixo desempenho. Estimava-se a princípio que a disciplina Ética, que tem como proposta explícita a discussão de valores morais e é oferecida no mesmo período cursado pelos respondentes no momento da pesquisa, fosse apresentar resultados mais positivos. Quanto à Semiologia, como os professores variam entre os grupos, a heterogeneidade pode explicar o baixo desempenho.

Oferecer disciplinas de bioética, seguindo as recomendações da Declaração Universal sobre Bioética e Direitos Humanos ${ }^{30}$, é outra estratégia importante, garantindo ambiente propício para a reflexão acerca dos conflitos morais existentes na prática profissional e dando suporte para as tomadas de decisão. Técnicas de ensino que valorizam metodologias ativas são potentes ferramentas para estimular a educação em valores. Podem ser aplicadas em nível institucional, com a implementação, por exemplo, da aprendizagem baseada em problemas, ou diretamente na disciplina, com mudanças no papel do docente e atividades que valorizam a participação individual e em pequenos grupos, estimulando a construção em conjunto de conhecimentos relacionados com a prática profissional ${ }^{31}$. Essas mudanças podem causar certa resistência, dado o desconforto causado pela passagem da ignorância para o conhecimento, como já narrado por Platão ${ }^{32}$ na alegoria da caverna.

A moral não é ensinada em uma única disciplina, tampouco somente em teoria. É aprendida por meio do exemplo, da prática, vivenciando conflitos e os abordando de maneira coletiva ${ }^{14,19,33,34}$. Valores morais ou virtudes, de acordo com Aristóteles ${ }^{35}$, são qualidades essenciais do caráter adquiridas pelo hábito e pela rotina com o propósito de alcançar a excelência; são comportamentos desejáveis que devem estar inseridos no currículo ${ }^{36}$.

As virtudes servem como referencial para uma educação em valores, capacitando as pessoas a agir de modo racional e justificado. A prática das virtudes deve ser planejada ao longo do currículo, e a postura do próprio professor deve servir de exemplo ${ }^{34}$. A educação moral é promovida quando o docente se torna modelo de atitudes morais, ensinando os alunos a viver moralmente e de modo coerente, alinhando o que diz e o que faz ${ }^{27,34}$. É possível ensinar moralidade sem agir moralmente ${ }^{37}$, mas a conduta moral é condição importante para que os professores se engajem no ensino de conteúdos morais.

Vale destacar a importância do planejamento das questões éticas e morais no currículo, dado que $82,4 \%$ dos estudantes reconhecem que o ensino dos valores morais está implícito nas disciplinas e atividades educativas. De acordo com esses dados, a falta de planejamento pedagógico sujeita a formação moral universitária à casualidade, dependente do perfil do professor ou de sua sensibilidade ao tema, não assumindo a competência moral como elemento basilar da formação profissional em saúde ${ }^{38}$.

Não basta reconhecer a importância da educação em valores para a formação universitária, é preciso inseri-la nas reuniões de professores, promover reflexões, capacitar docentes e até mesmo 
instituir educação permanente, visto que muitos não têm formação pedagógica específica ${ }^{14,33,39,40}$. Além disso, faz-se necessário repensar as propostas curriculares dos cursos de pós-graduação stricto sensu, que frequentemente deixam essa lacuna durante a formação de professores ao priorizar a pesquisa ${ }^{39}$.

Como limitações do estudo, aponta-se que apenas $85 \%$ dos alunos elegíveis responderam ao questionário, ainda que o percentual de respostas tenha sido elevado. Outra limitação diz respeito ao conhecimento dos participantes sobre os conceitos de valores morais. Pesquisa com alunos e professores de medicina mostrou diferenças no grau de definição de valores como "cortesia" e "simplicidade", que foram os mais claros, enquanto "honestidade" foi o valor mais difícil de conceituar ${ }^{41}$. Nessa perspectiva, seria interessante aliar a análise quantitativa à definição de cada participante sobre valores morais, contribuindo para aprofundar a compreensão sobre a temática. Uma última limitação da pesquisa concerne ao fato de que se inseriram valores morais em número limitado e em questões fechadas, não possibilitando ao participante incluir outro valor que julgasse importante acrescentar.

\section{Considerações finais}

"Respeito", "responsabilidade", "paciência" e "humildade", assim como "prudência" e "confiança", foram os valores morais listados pelos estudantes como essenciais para a formação médica. Os participantes reconhecem a importância da educação moral para a prática profissional e se mostram sensíveis ao tema. No entanto, para que a educação em valores seja efetiva, os professores devem se conscientizar de seu papel de caráter social. Consequentemente, é necessário capacitar docentes e instituir educação permanente para que a formação moral não seja produto da casualidade nem continue à margem dos currículos.

\section{Referências}

1. Steiner-Hofbauer V, Schrank B, Holzinger A. What is a good doctor? Wien Med Wochenschr [Internet]. 2018 [acesso 15 abr 2020];168(15-16):398-405. DOI: 10.1007/s10354-017-0597-8

2. Gracia D. Pensar a bioética: metas e desafios. São Paulo: Loyola; 2010.

3. Burgess A, Oates K, Goulston K. Role modelling in medical education: the importance of teaching skills. Clin Teach [Internet]. 2016 [acesso 15 abr 2020];13(2):134-7. DOI: 10.1111/tct.12397

4. Ferrari AG, Silva CM, Siqueira JE. Ensino de bioética nas escolas de medicina da América Latina. Rev. bioét. (Impr.) [Internet]. 2018 [acesso 15 abr 2020];26(2):228-34. DOI: 10.1590/1983-80422018262243

5. Conselho Nacional de Educação. Parecer CNS/CES no 1.133/2001. Diretrizes curriculares nacionais dos cursos de graduação em enfermagem, medicina e nutrição. Diário Oficial da União [Internet]. Brasília, 3 out 2001 [acesso 15 abr 2020]. Disponível: https://bit.ly/35fdz84

6. Conselho Nacional de Educação. Resolução CNE/CES no 3, de 20 de junho de 2014. Institui diretrizes curriculares nacionais do curso de graduação em medicina e dá outras providências. Diário Oficial da União [Internet]. Brasília, 23 jun 2014 [acesso 15 abr 2020]. Disponível: https://bit.ly/2ZhS5nf

7. Ferreira MJM, Ribeiro KG, Almeida MM, Sousa MS, Ribeiro MTAM, Machado MMT, Kerr LRFS. Novas diretrizes curriculares nacionais para os cursos de medicina: oportunidades para ressignificar a formação. Interface Comun Saúde Educ [Internet]. 2019 [acesso 15 abr 2020];23(supl 1):e170920. DOI: 10.1590/interface.170920

8. Araújo UF, Puig JM. Educação e valores. 2ª ed. Arantes VA, organizadora. São Paulo: Summus; 2007.

9. Serodio A, Kopelman BI, Bataglia PUR. A promoção das competências moral e democrática: por uma virada educacional da bioética. Rev. bioét. (Impr.) [Internet]. 2016 [acesso 15 abr 2020];24(2):23542. DOI: $10.1590 / 1983-80422016242123$

10. Puig Rovira JM, Martín García X. Para un currículum de educación en valores. Folios [Internet]. 2015 [acesso 15 abr 2020];(41):7-22. Disponível: https://bit.ly/35cGLwu

11. MacIntyre A. Dependent rational animals: why human beings need the virtues? Chicago: Open Court; 2001.

12. Hernando A, Diez-Vega I, Lopez Del Hierro M, Martínez-Alsina M, Diaz-Meco R, Busto MJ et al. Ethical values in college education: a mixed-methods pilot study to assess health sciences students' perceptions. BMC Med Educ [Internet]. 2018 [acesso 15 abr 2020];18:289-300. DOI: 10.1186/ s12909-018-1396-7

13. Hojat M, Vergare MJ, Maxwell K, Brainard G, Herrine SK, Isenberg GA et al. The devil is in the third year: a longitudinal study of erosion of empathy in medical school. Acad Med [Internet]. 2009 [acesso 15 abr 2020];84(9):1182-91. DOI: 10.1097/ACM.0b013e3181b17e55 
14. Seoane L, Tompkins LM, De Conciliis A, Boysen PG 2nd. Virtues education in medical school: the foundation for professional formation. Ochsner J [Internet]. 2016 [acesso 15 abr 2020];16(1):50-5. Disponível: https://bit.ly/3oDgJsJ

15. Maldonado MC, Majía IS, Ulloa LV. Valores que se fomentan en la escuela universitaria de las ciencias de la salud. Rev Cient Esc Univ Cienc Salud [Internet]. 2015 [acesso 15 abr 2020];2(1):29-36. Disponível: https://bit.ly/2GBPoWZ

16. Rabow MW, Evans CN, Remen RN. Professional formation and deformation: repression of personal values and qualities in medical education. Fam Med [Internet]. 2013 [acesso 15 abr 2020];45(1):13-8. Disponível: https://bit.ly/2GI2mCM

17. Gilligan C. In a different voice: psychological theory and women's development. Cambridge: Harvard; 1982.

18. Moyano LG. La ética del cuidado y su aplicación en la profesión enfermera. Acta Bioeth [Internet]. 2015 [acesso 15 abr 2020];21(2):311-7. Disponível: https://bit.ly/32aOt8w

19. Karches KE, Sulmasy DP. Justice, courage, and truthfulness: virtues that medical trainees can and must learn. Fam Med [Internet]. 2016 [acesso 15 abr 2020];48(7):511-6. Disponível: https://bit.ly/376dNz3

20. Passos E, Carvalho YM. A formação para o SUS abrindo caminhos para a produção do comum. Saúde Soc [Internet]. 2015 [acesso 15 abr 2020];24(supl 1):92-101. DOI: 10.1590/s0104-12902015s01008

21. Montanari PM. Formação para o trabalho no ensino das graduações em saúde. Saúde Soc [Internet]. 2018 [acesso 15 abr 2020];27(4):980-6. DOI: 10.1590/s0104-12902018180974

22. Japiassú H, Marcondes D. Dicionário básico de filosofia. 3ạ ed. Rio de Janeiro: Jorge Zahar; 2001.

23. Conselho Federal de Medicina. Resolução CFM no 2.217, de 27 de setembro de 2018. Aprova o Código de Ética Médica. Diário Oficial da União [Internet]. Brasília, no 211, p. 179, 1ํ nov 2018 [acesso 28 maio 2020]. Seção 1. Disponível: https://bit.ly/3jXVNdv

24. Lehmann LS, Sulmasy LS, Desai S. Hidden curricula, ethics, and professionalism: optimizing clinical learning environments in becoming and being a physician: a position paper of the American College of Physicians. Ann Intern Med [Internet]. 2018 [acesso 15 abr 2020];168(7):506-8. DOI: 10.7326/M17-2058

25. Farias JB J. Hans Jonas e Paul Ricoeur: a ética da responsabilidade à luz da alteridade. Sapere Aude [Internet]. 2013 [acesso 15 abr 2020];4(8):243-53. Disponível: https://bit.ly/3IZDI65

26. Sennett R. El respeto: sobre la dignidad del hombre en un mundo de desigualdad. Barcelona: Anagrama; 2003.

27. Martínez M, Esteban F, Jover G, Payà M, organizadores. La educación, en teoría. Madrid: Síntesis; 2016.

28. Domingues KG, Almeida IMMZP. Sociedade, educação e narcisismo da relação do professor com o não-saber [Internet]. In: Anais do V Colóquio Internacional Educação e Contemporaneidade; 21-23 set 2011; São Cristovão. São Cristóvão: Educon; 2011 [acesso 15 abr 2020]. Disponível: https://bit.ly/3277clg

29. Almeida PF, Bastos MO, Condé MA, Macedo NJ, Feteira JM, Botelho FP, Silva RL. Trabalho de campo supervisionado II: uma experiência curricular de inserção na atenção primária à saúde. Interface Comun Saúde Educ [Internet]. 2016 [acesso 15 abr 2020];20(58):777-86. DOI: 10.1590/1807-57622015.0692

30. Organização das Nações Unidas. Declaração universal sobre bioética e direitos humanos [Internet]. Paris: Unesco; 2006 [acesso 28 maio 2020]. Disponível: https://bit.ly/2F8LO6k

31. Marques LMNSR. As metodologias ativas como estratégias para desenvolver a educação em valores na graduação de enfermagem. Esc Anna Nery [Internet]. 2018 [acesso 15 abr 2020];22(3):e20180023. DOI: 10.1590/2177-9465-ean-2018-0023

32. Platão. A república. 3ạ ed. São Paulo: Edipro; 2019.

33. Camps VC. Los valores de la educación. 7ạ ed. Madrid: Anaya; 2000.

34. Passi V, Johnson S, Peile E, Wright S, Hafferty F, Johnson N. Doctor role modelling in medical education: BEME Guide no. 27. Med Teach [Internet]. 2013 [acesso 15 abr 2020];35(9):e1422-36. DOI: 10.3109/0142159X.2013.806982

35. Aristóteles. Ética a Nicômaco. 4ạ ed. São Paulo: Edipro; 2014.

36. Román B. Formación del carácter: dar lo que uno tiene. In: Esteban F, editor. La formación del carácter de los maestros. Barcelona: Universitat de Barcelona; 2016. p. 19-30.

37. Fenstermacher GD, Osguthorpe RD, Sanger MN. Teaching morally and teaching morality. Teach Educ Q [Internet]. 2009 [acesso 15 abr 2020];36(3):7-19. DOI: 10.2307/23479186

38. Esteban F, Buxarrais MR. El aprendizaje ético y la formación universitaria: más allá de la casualidad. Teor Educ [Internet]. 2004 [acesso 15 abr 2020];16:91-108. Disponível: https://bit.ly/2ZgO9TS

39. Freitas DA, Santos EMS, Lima LVS, Miranda LN, Vasconcelos EL, Nagliate PC. Saberes docentes sobre o processo de ensino-aprendizagem e sua importância para a formação profissional em saúde. Interface Comun Saúde Educ [Internet]. 2016 [acesso 15 abr 2020];20(57):437-48. DOI: 10.1590/1807-57622014.1177

40. Serodio A, Kopelman BI, Bataglia PUR. The promotion of medical students' moral development: a comparison between a traditional course on bioethics and a course complemented with the Konstanz method of dilemma discussion. Int J Ethics Educ [Internet]. 2016 [acesso 15 abr 2020];1(1):81-9. DOI: 10.1007/s40889-016-0009-8 
41. Vargas Jorge Z. Valores humanos del médico del siglo XXI: grado de conocimiento de los estudiantes y docentes de la carrera de medicina de la U.M.S.A. 2017. Cuad Hosp Clín [Internet]. 2018 [acesso 11 set 2020];59(1):41-50. Disponível: https://bit.ly/3hbUgyX

\section{Participação dos autores}

Lumaira Maria Nascimento Silva da Rocha Marques coordenou o estudo. Vitor Corradini Milioni e Weydler Campos Hottz Corbiceiro coletaram e analisaram dados. Sandra Costa Fonseca fez a revisão metodológica e a análise estatística dos dados. Todos os autores contribuíram para a redação final do artigo.

\section{Correspondência}

Lumaira Maria Nascimento Silva da Rocha Marques - Rua Aires Saldanha, 136/304 CEP 22030-030. Rio de Janeiro/RJ, Brasil.

Lumaira Maria Nascimento Silva da Rocha Marques - Doutora - lumaira_@hotmail.com (iD) 0000-0002-1167-273X

Sandra Costa Fonseca - Doutora - sandracfonseca@yahoo.com.br

(iD) 0000-0001-5493-494X

Vitor Corradini Milioni - Graduado - vitormilioni@id.uff.br

(D) 0000-0001-6651-1442

Weydler Campos Hottz Corbiceiro - Graduado - weydlerhottz@id.uff.br

(iD) $0000-0002-4730-4744$

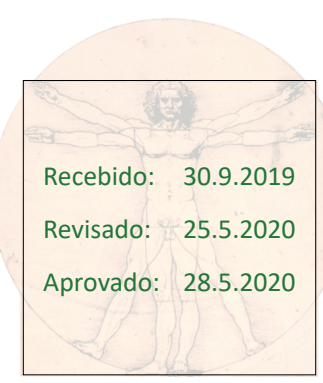




\section{Anexo}

\section{Questionário}

\section{Perfil socioeconômico}

1. Idade:

2. Sexo: ( ) Feminino ( ) Masculino

3. Estado civil: ( ) Solteiro ( ) Casado ( ) Viúvo ( ) Divorciado ( ) Outro:

4. Cor: ( ) Branca ( ) Preta ( ) Parda ( )Amarela ( ) Indígena

5. Religião: ( ) Católico （）Evangélico （）Espírita （）Testemunha de Jeová （）Ateu ( ) Outra:

6. Renda familiar: （） De 1 a 5 salários mínimos （） De 6 a 11 salários mínimos （） De 12 a 16 salários mínimos ( ) De 17 a 22 salários mínimos ( ) Mais de 23 salários mínimos

\section{Questões sobre valores morais}

7. Que valores morais você acredita que têm sido estimulados durante sua graduação? Você pode assinalar mais de uma alternativa.
( ) Respeito
( ) Justiça
( ) Misericórdia
( ) Esperança
( ) Verdade
( ) Generosidade
( ) Humildade
( ) Responsabilidade
( ) Prudência
( ) Confiança
( ) Caridade
( ) Concórdia
( ) Benevolência
( ) Coragem
( ) Gratidão
( ) Paciência

8. Quais valores morais você considera importantes para sua formação? Você pode assinalar mais de uma alternativa.
( ) Respeito
( ) Justiça
( ) Verdade
( ) Generosidade
( ) Misericórdia
( ) Esperança
( ) Prudência
( ) Confiança
( ) Humildade
( ) Responsabilidade
( ) Benevolência
( ) Coragem
( ) Caridade
( ) Concórdia
( ) Gratidão
( ) Paciência

9. Qual(is) disciplina(s) discutiu(ram) ou proporcionou(aram) vivência desses valores morais? Você pode assinalar mais de uma alternativa.

\begin{tabular}{|c|c|c|c|c|c|}
\hline ( ) & Biologia Geral I & ( ) & Epidemiologia II & ( ) & Semiologia \\
\hline ( ) & Neurobiologia & ( ) & Cardiologia & ( ) & Radiologia \\
\hline ( ) & Saúde e Sociedade I & ( ) & Dependência Química & $(1)$ & Saúde e Sociedade IV \\
\hline$(1)$ & TCSI-A & ( ) & Dermatologia & ( ) & TCS III - A \\
\hline ( ) & Biologia Celular e Molecular & ( ) & DIP & $(1)$ & TCS IV - A \\
\hline$(1)$ & Psicologia Médica I & ( ) & DHE & $(1)$ & Saúde e Sociedade V \\
\hline$(1)$ & Saúde e Sociedade II & ( ) & Gastroenterologia & ( ) & Endocrinologia \\
\hline ( ) & Morfologia I & ( ) & Ginecologia & ( ) & Epidemiologia IV \\
\hline ( ) & Imunobiologia & ( ) & Obstetrícia & ( ) & Farmacologia Clínica \\
\hline$(1)$ & Epidemiologia I & ( ) & Hematologia & ( ) & Medicina Legal \\
\hline ( ) & TCSI-B & ( ) & ITU & $(1)$ & Oncologia \\
\hline ( ) & Epidemiologia II & ( ) & Neurologia & ( ) & Ortopedia \\
\hline$(1)$ & Saúde e Sociedade III & ( ) & PGM & ( ) & Psiquiatria \\
\hline$(1)$ & Morfologia II & ( ) & Pneumologia & ( ) & Reumatologia \\
\hline$(1)$ & Fisiologia VI & ( ) & Antibioticoterapia & ( ) & Toxicologia \\
\hline$(1)$ & TCS $\|-A$ & ( ) & TCS III - B & ( ) & Anatomia Patológica \\
\hline ( ) & MAD I & ( ) & PGS III & ( ) & Patologia Clínica \\
\hline ) & Fisiologia VII & ( ) & Neuropsiquiatria Infantil & ( ) & PAPP \\
\hline ( ) & PGS I & ( ) & Anestesiologia & ( ) & Ética \\
\hline ( ) & Morfologia III & ( ) & Cirurgia Geral & ( ) & AMC \\
\hline
\end{tabular}




\begin{tabular}{|c|c|c|c|c|c|}
\hline ( ) & Neurocirurgia & $(1)$ & MAD II & $(1)$ & Cirurgia Plástica \\
\hline ) & TCS II-B & $1)$ & Cirurgia Torácica & $(1)$ & Psicologia Médica II \\
\hline ) & Geriatria & $(1)$ & PGS ॥ & $(1)$ & Imunologia Clínica \\
\hline ) & Pediatria & $1)$ & Nefrologia & $(1)$ & Patologia \\
\hline ) & Neonatologia & $1)$ & MEDLAB & $(1)$ & Oftalmologia \\
\hline 1 & Farmacologia & $1)$ & Otorrinolaringologia & $(1)$ & Genética \\
\hline ) & Urologia & $(1)$ & Optativa(s). Qual(is)? & & \\
\hline
\end{tabular}

TCS: Trabalho de Campo Supervisionado; DIP: Doenças Infectoparasitárias; DHE: Distúrbios Hidroeletrolíticos; ITU: Infecção do Trato Urinário; PGM: Patologias Genitais Masculinas; MAD: Mecanismo de Agressão e Defesa; PGS: Planejamento e Gerência em Saúde; PAPP: Programa de Apoio Psicopedagógico; AMC: Anatomia Médico Cirúrgica; MEDLAB: Medicina Laboratorial

10. Qual método pedagógico utilizado proporcionou melhores discussões a respeito dos valores morais? Você pode assinalar mais de uma alternativa.

$\begin{array}{llll}\text { ( ) Aula expositiva } & (\text { ) Discussões em pequenos grupos } & (\text { ) Discussão de casos clínicos } & (\text { ) Portfólio } \\ \text { ( ) Vivência prática } & \text { ( ) Discussão de filmes } & (\text { ) Seminários } & (\text { ) Debates }\end{array}$

( ) Outros:

11. Você acredita que os valores morais têm sido trabalhados de maneira:

( ) Explícita no conteúdo das disciplinas

( ) Implícita no conteúdo das disciplinas

12. Como tem sido a relação entre discentes e docentes durante sua graduação?

( ) Vertical/autoritária ( ) Horizontal/dialogada

13. Você acha que as discussões sobre valores morais contribuirão para a sua prática profissional?
( ) Muito
( ) Pouco
( ) Não 